\title{
THE 3D SURVEY OF THE ROMAN BRIDGE OF SAN LORENZO IN PADOVA (ITALY): A COMPARISON BETWEEN SFM AND TLS METHODOLOGIES APPLIED TO THE ARCH STRUCTURE
}

\author{
F. Carraro ${ }^{1 *}$, M. Monego ${ }^{2}$, C. Callegaro ${ }^{2}$, A. Mazzariol ${ }^{1}$, M. Perticarini ${ }^{2}$, A. Menin ${ }^{2}$, V. Achilli ${ }^{2}$, J. Bonetto ${ }^{1}$, A. Giordano ${ }^{2}$ \\ ${ }^{1}$ Dept. of Cultural Heritage, University of Padua, Italy - (filippo.carraro.1, alessandro.mazzariol, jacopo.bonetto) @ unipd.it \\ ${ }^{2}$ Dept. of Civil, Environmental and Architectural Engineering, University of Padua, Italy - (michele.monego, chiara.callegaro, \\ maurizio.perticarini, andrea.menin, vladimiro.achilli, andrea.giordano) @ unipd.it
}

Commission II, WG II/8

KEY WORDS: 3D survey, Photogrammetry, TLS, Geomatics, Cultural Heritage, Archaeology, Roman Bridge, Cloud Compare.

\begin{abstract}
:
3D survey methodologies are widely applied to the Cultural Heritage, employing both TLS and close-range photogrammetry with SfM techniques. Laser scanning produces models with high metric reliability and accuracy, whereas the main quality of the 3D photogrammetry is the result in term of photorealistic representation. Many studies have been conducted about the comparison and the integration of these different approaches and the aim of this paper is to contribute with a peculiar case study: the underground Roman bridge of San Lorenzo in Padova (Italy). The investigation regards the resulting point clouds of the intrados (or inner curve) of the central arch, comparing them and providing graphical and analytical outputs. The proposed workflow has the purpose to be a simple but valid tool to detect and evaluate geometrical differences, their significativity and the reliability of the 3D models.
\end{abstract}

\section{INTRODUCTION}

The project "PD Invisible" of the University of Padova has provided an opportunity for a focus on three-dimensional survey techniques in the Cultural Heritage $(\mathrm{CH})$ context, strengthening the cooperation between the Department of Cultural Heritage and the Department of Civil, Environmental and Architectural Engineering. The project, funded by the European Social Fund, aims to hand back to the city of Padova the awareness of a rich heritage hidden under the modern city's surface. Monuments of the Roman age, still surviving under the road level of the city, yet no more accessible or visible, are being surveyed and simultaneously studied through archives investigations in order to turn this archaeological knowledge into a three-dimensional story of the past of the city. A new life will be given to this past by delivering an Augmented Reality application, showing the hidden monuments directly on the site. A parallel development plan is collecting these surveys into a Historical BIM project, aimed to a semantic enrichment and the application of analysis and maintenance techniques. Hence, the topic of the topographic and three-dimensional survey acquires a crucial relevance for a proper and accurate fulfilment of the project. A peculiar attention has been paid to this step of the project, especially concerning models' accuracy and precision, both geometrical and geographical. The availability of different tools for surveying purposes (cameras for photogrammetry and laser scanners) has been providing interesting chances for comparison and accuracy assessment. Surveys were performed in conditions that were anything but optimal, usually in dark, narrow and damp chambers, stressing the efficiency of instruments. Moreover, the need for high resolution models for scientific purposes diverges with a demand for lightness and attractiveness from the end users, the public, that is notspecialized and no well-equipped.

The selected monument for this contribution is the Roman bridge of San Lorenzo, a three-arches bridge, made of local stone and dated back to the 1st century B.C. (Galliazzo, 1971; Bonetto et al., 2017) (Figure 1). Along with the development of the city a gradual narrowing of the river caused two arches to be buried, whereas the eastern one was used as a bridge until the middle of the 20th century, when embanking interventions took place all along the city. The arches are now preserved in a narrow chamber underground that hardly makes it visible and accessible.
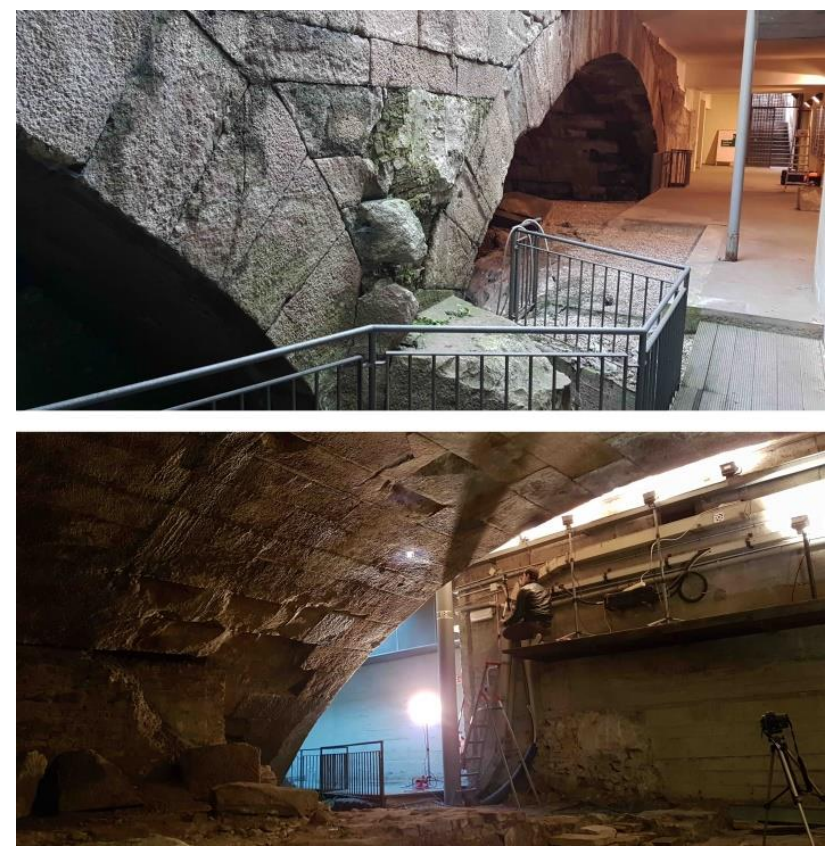

Figure 1. The Roman bridge of San Lorenzo: the first arch (above) and the central arch (below) where the chamber narrows and the light fades out.

\footnotetext{
* Corresponding author
} 
This contribution aims to provide the project with a referencing report about the employed surveying processes and the quality of the obtained models and their next processing. At the same time it could provide some accessible guidelines for a new generation of $\mathrm{CH}$ scholars increasingly impelled to autonomously apply and evaluate such survey techniques, for documentation, conservation and preservation purposes.

\section{STATE OF ART}

The issue actually is not a recent one. The comparison between laser scanning and image-based modelling has been a popular topic since they became competitive surveying methods (Baltsavias, 1999; Guarnieri et al., 2004). The comparison concerns costs of processing, acquisition times, but it is mainly a matter of accuracy and reliability. Though many contributions are focused on laser scanning accuracy (Boehler, 2003; Lichti, Gordon, 2004) TLS models are usually taken as a reference when assessing photogrammetric outcomes. A wide range of publications is available on this topic, even in relation with $\mathrm{CH}$. Different procedures of observation and comparison have been tested (Grussenmeyer et al., 2008; Bolognesi et al., 2014; Bosche et al., 2015; Micheletti et al., 2015; Broome 2016) and they have all usually attested the efficacy of both surveying techniques in the field of $\mathrm{CH}$. Nevertheless, the importance of this issue is still effective, since new strong photogrammetric software appear and new and efficient cameras become available. The demand for low-cost survey techniques in the field of $\mathrm{CH}$ makes the application of commercial and noninvasive sensors particularly interesting, especially for nonexperts in metrology issues. Action cameras and, more recently, staedicams, have started to be a central topic, with a particular focus on calibration methods and geometric validation (Remondino, Fraser, 2006; Fraser, 2013; Balletti et al., 2014; Fiorillo et al., 2016; Calantropio et al., 2018). Being sensitive to these demands, we have faced a case study where different approaches are tested, but accuracy remains an essential requirement. The case deals with a peculiar surface, the concave intrados of a bridge enclosed in an underground chamber, which makes best practices of photogrammetry less practicable. The curved shape and the environmental conditions could be considered a stimulating circumstance to be evaluated and shared.

\section{LASER SCANNING AND PHOTOGRAMMETRIC SURVEY}

The 3D survey of the bridge was performed by applying two different approaches: a range-based survey with a laser scanner, and two image-based surveys, based on Structure from Motion, by means of a SLR camera and an action camera (Figure 2).
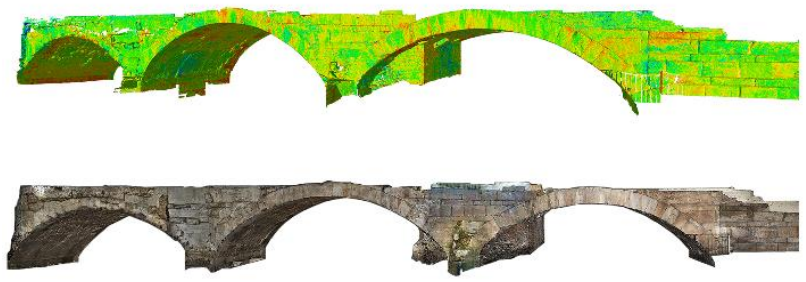

Figure 2. The point clouds of the bridge generated by laser scanning (above) and by SfM (below).
Afterwards, results were geometrically compared to estimate their accuracy and overlapping. The three surveys were performed in the same period and were referenced by the same reference network. The TLS survey has been executed in order to obtain the complete 3D model of the bridge with high reliability in terms of metric and geometric accuracy. The Leica ScanStation P20 (Table 1), a time-of-flight scanner, was employed with the support of Leica HDS black/white target for the registration phase. A total of 18 scans were acquired, with resolution setting of $6,3 \mathrm{~mm} @ 10 \mathrm{~m}$, and 78 target were measured. The registration process were performed by the software Leica Cyclone with a mean absolute error, checked on the targets, of $3 \mathrm{~mm}$. 24 vertices (mainly corresponding with the scanning points) were measured as reference network using a total station Leica TCR1201. Thanks to the GNSS acquisitions (with Leica Viva GS15-CS15) in 2 external vertices it was possible to obtain the geographic coordinates and then insert the network in the national cartographic Gauss-Boaga reference system.

\begin{tabular}{|c|c|c|c|c|}
\hline \multicolumn{5}{|c|}{ Leica ScanStation P20 } \\
\hline \multicolumn{5}{|l|}{$\begin{array}{l}\text { Accuracy of } \\
\text { single } \\
\text { Measurement }\end{array}$} \\
\hline $\begin{array}{l}\text { 3D Position } \\
\text { Accuracy }\end{array}$ & \multicolumn{4}{|c|}{$3 \mathrm{~mm}$ at $50 \mathrm{~m} ; 6 \mathrm{~mm}$ at $100 \mathrm{~m}$} \\
\hline Linearity error & \multicolumn{4}{|c|}{$\leq 1 \mathrm{~mm}$} \\
\hline Angular accuracy & \multicolumn{4}{|c|}{$8 "$ horizontal; 8" vertical } \\
\hline $\begin{array}{c}\text { Target } \\
\text { acquisition }\end{array}$ & \multicolumn{4}{|c|}{$2 \mathrm{~mm}$ standard deviation up to $50 \mathrm{~m}$} \\
\hline \multirow[t]{5}{*}{ Range noise } & Range & $\begin{array}{l}\text { Black } \\
(10 \%)\end{array}$ & $\begin{array}{l}\text { Gray } \\
(28 \%)\end{array}$ & $\begin{array}{l}\text { White } \\
(100 \%)\end{array}$ \\
\hline & $10 \mathrm{~m}$ & $\begin{array}{c}0.8 \mathrm{~mm} \\
\mathrm{rms}\end{array}$ & $\begin{array}{c}0.5 \mathrm{~mm} \\
\mathrm{rms}\end{array}$ & $\begin{array}{c}0.4 \mathrm{~mm} \\
\mathrm{rms}\end{array}$ \\
\hline & $25 \mathrm{~m}$ & $\begin{array}{c}1.0 \mathrm{~mm} \\
\mathrm{rms}\end{array}$ & $\begin{array}{l}0.6 \mathrm{~mm} \\
\mathrm{rms}\end{array}$ & $\begin{array}{l}0.5 \mathrm{~mm} \\
\mathrm{rms}\end{array}$ \\
\hline & $50 \mathrm{~m}$ & $\begin{array}{c}2.8 \mathrm{~mm} \\
\mathrm{rms}\end{array}$ & $\begin{array}{c}1.1 \mathrm{~mm} \\
\mathrm{rms}\end{array}$ & $\begin{array}{c}0.7 \mathrm{~mm} \\
\mathrm{rms}\end{array}$ \\
\hline & $100 \mathrm{~m}$ & $\begin{array}{l}9.0 \mathrm{~mm} \\
\mathrm{rms}\end{array}$ & $\begin{array}{l}4.3 \mathrm{~mm} \\
\mathrm{rms}\end{array}$ & $\begin{array}{c}1.5 \mathrm{~mm} \\
\mathrm{rms}\end{array}$ \\
\hline
\end{tabular}

Table 1. System performances of the laser scanner Leica ScanStation P20.

The photogrammetric surveys have been performed separately with a full frame SLR camera Nikon D610 and with a GoPro Hero5 Black (Table 2).

\begin{tabular}{|l|l|l|}
\hline & Nikon D610 & GoPro Hero5 Black \\
\hline Camera type & SLR camera & Action camera \\
\hline Sensor type & CMOS & CMOS \\
\hline Sensor size & $\begin{array}{l}35.9 \times 24 \mathrm{~mm} \\
\text { (full frame) }\end{array}$ & $1 / 2.3 "-6.17 \times 4.55 \mathrm{~mm}$ \\
\hline Effective resolution & 24 megapixels & 12 megapixels \\
\hline Focal length & $35 \mathrm{~mm}$ & $\begin{array}{l}3 \mathrm{~mm} \\
(21 \mathrm{~mm} \text { equivalent })\end{array}$ \\
\hline
\end{tabular}

Table 2. Technical specifications of the cameras.

Both the cameras have been previously calibrated on the same site with an Agisoft Chessboard pattern. And both the surveys have followed a similar method, based on a orthogonal grid 
$(0.50 \times 0.50 \mathrm{~m}$ for the action camera, a less regular one for the SLR camera) and on the acquisition of the vault with cameras generally normal to the captured surface. A sample of convergent images have been also added to the dataset. The maximum distance achievable from the bridge has been on average 2.5 meters. The major difference in image capture has been the lighting system. A static lighting arrangement has been used with the action camera: an array of 6 halogen floodlights has ensured an homogeneous light over the whole vault (or the façade) during the entire capturing session. The SLR camera survey, on the other hand, has been supported with an additional mobile floodlight, moving consistently with the camera's line of sight. Such an arrangement has granted an homogeneous lighting and at the same time it has got rid of most of the shadows.

The following processing of the survey, performed in Agisoft Metashape 1.5.1 has returned two dense point clouds, with ground resolution of $0.3 \mathrm{~mm} /$ pixel (SLR camera) and 0.9 $\mathrm{mm} /$ pixel (GoPro). The accuracy has been estimated by applying a set of 10 control points and 4 check points, whose positions on the structure have been influenced by the necessity of keep the arch surface clear from external object, in order to obtain an undisturbed graphical rendering (Figure 3).

The obtained error estimates reported by the software have been, for the full frame camera, of $1.4 \mathrm{~mm}$ RMSE on control points and $2.4 \mathrm{~mm}$ RMSE on check points, whereas the action camera survey has produced a control points RMSE of $4.2 \mathrm{~mm}$ and a check points RMSE of $7.0 \mathrm{~mm}$.

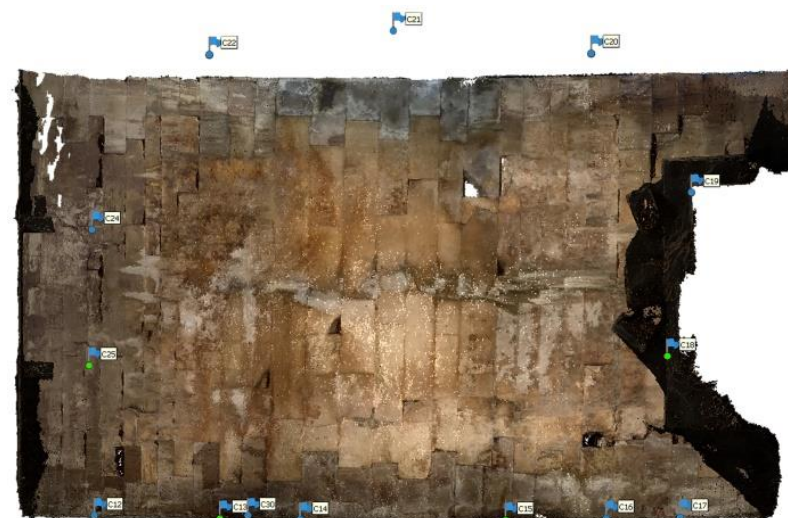

a

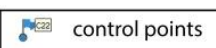
check points

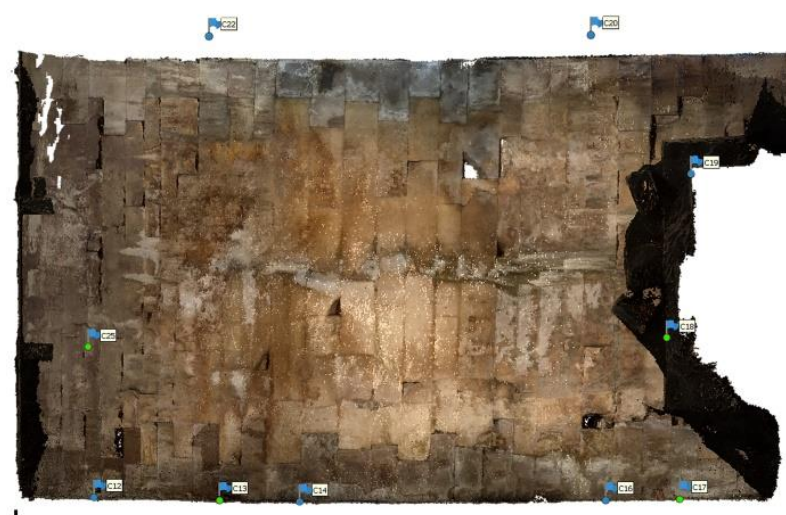

b

Figure 3. Distribution of control and check points on the arch for the processing of the survey with SLR (a) and the one with the action camera (b)
Nevertheless, since the peculiarity of the surveyed surface and of the acquisition settings and procedures, a wider and homogeneous assessment was required. Using the terrestrial laser scanning as a reference, every single portion of the clouds can be evaluated.

\section{MODELS COMPARISON}

The analysis shown in this work has concerned the lower surface of the central arch of the bridge. SfM models have been compared with a single cloud from the laser scanning model. The latter has been considered as the reference cloud in the comparison phase because of the widely recognized geometric reliability of the TLS methodology that provides high accuracy in the single scan and, depending on the quality of the registration, even in the global model.

Two software have been applied in this phase, using different algorithms for the cloud-to-cloud calculation of the geometric differences: Cloud Compare (free and open source), with the M3C2 plugin, and 3D Reshaper (commercial software) applying its compare/inspection tool.

\subsection{Distance calculation: Cloud Compare plugin M3C2}

For the comparison between the 3D models we have used the plugin $\mathrm{M} 3 \mathrm{C} 2$ of Cloud Compare. The software allows itself a distance calculation tool (C2C), for cloud-to-cloud, cloud-tomesh and mesh-to-mesh comparison but it only provides absolute distances and few setting parameters. For more robust and signed results $\mathrm{M} 3 \mathrm{C} 2$ is a more adequate solution.

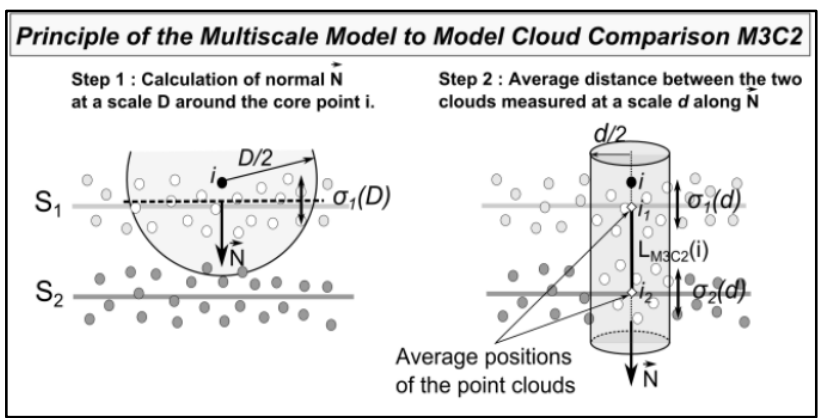

Figure 4. Description of the M3C2 algorithm and the two userdefined parameters D (normal scale) and d (projection scale) (Lague et al., 2013).

We firstly describe how the $\mathrm{M} 3 \mathrm{C} 2$ algorithm operates to measure the distance between two points clouds and which parameters have been set up for the calculation. The calculation is based on a set of "core" points for which one distance and confidence interval is calculated. The core points are generally a sub-sampled version of the reference cloud, but the calculations are performed on the original raw full data. This option allows to speed up the processing and considers the fact that calculation results are generally needed at a lower, more uniform spatial resolution (e.g. $10 \mathrm{~cm}$ ) than the raw irregular point spacing of high density scans (e.g. $1 \mathrm{~cm}$ or less). The point clouds themselves may also be used directly (each point is a core point) (Lague et al., 2013). The other parameters requested by the computation are the normal scale, the projection scale and the max depth. The normal scale is the diameter of the spherical neighbourhood extracted around each core point to compute a local normal. A cylinder oriented following these normals is the volume used as a search region to detect equivalent points in the other cloud. The diameter of this 
cylinder is the value of the projection scale while its height (in both directions) corresponds to the max depth value (Figure 4). High values in these parameters bring a smaller influence of the local surface roughness, but on the other hand more points would be averaged in all the local areas and the processing would be slower (Lague et al. 2013). Furthermore, the tool gives the option of inserting a registration error value that is typically due to the error that results from scans registration or, as in our case, to the georeferencing of the single scan on the targets. This field provides the output scalar field "significant change", about the significance of the calculated displacement, and it is taken into account during the confidence computation for each point. The $\mathrm{M} 3 \mathrm{C} 2$ parameters used for our computation are shown in the table below (Table 3 ).

\begin{tabular}{|l|l|}
\hline \multicolumn{2}{|c|}{ M3C2 parameters [m] } \\
\hline Normals scale (D) & 0.050 \\
\hline Projection scale (d) & 0.100 \\
\hline Max depth & 0.200 \\
\hline Core point subsampling & 0.010 \\
\hline Registration error & 0.003 \\
\hline
\end{tabular}

Table 3. M3C2 input parameters for the distance calculation.

\subsection{Distance calculation: 3DReshaper compare/inspect tool.}

In order to have an alternative comparison tool the commercial software 3D Reshaper and its function of cloud-to-cloud inspection have been used. Unlike Cloud Compare, 3D Reshaper allows less control on the computation and does not provide export data for further statistical analysis.

For the distance calculation, each point is projected in the direction of the local normal of the cloud on a local plane. The measured distance is not the closest distance to a point of the target cloud, but the closest distance to a local plane of the target cloud. The different options regards these three choices: 3D projection, 2D projection or thin part scanned from two sides. This affects the construction of the local plane. We have chosen the 3D projection that, as shown in Figure 5 provides the better configuration for a correct distance calculation.

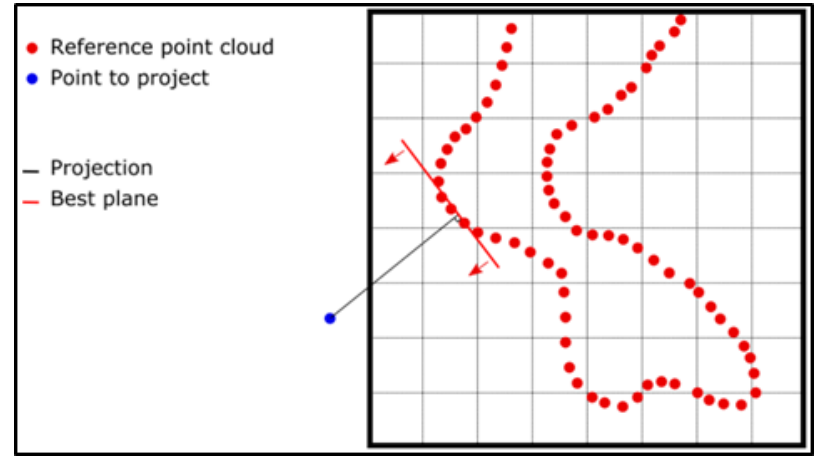

Figure 5. 3D projection option for the 3D Reshaper clouds inspection: the local plane is the closest one along the normal direction.

The same function has been used for the comparison of linear objects such as the polylines extracted from the 3D models along some representative portions of the clouds.

In both cases (clouds or polylines inspections) the only parameter that can be set is the maximum inspection distance beyond which the calculation is not performed. Its value has been set on $0.200 \mathrm{~m}$ (corresponding to the max depth value of M3C2).

\section{RESULTS}

The comparison between the model provides a set of outputs that comprehends 3D visualizations of point clouds with different scalar fields, the related data and their statistics.

In the Figures 6, 7, 8, 9 and Tables 4 and 5 the results of the point clouds distance calculations produced by Cloud Compare and (only in Figures 6b and Figure 8b) by 3D Reshaper, are presented.

Every 3D model has a color scale bar that graphically shows the entity of the calculated distance between the models in that specific point. In Figures $8 \mathrm{c}$ and $11 \mathrm{c}$ the areas of significant change in the model are shown. They allows to focus on the parts in which the distance values exceed the value of registration error (in this case, the registration not between different scans but of the TLS scan on the reference network).
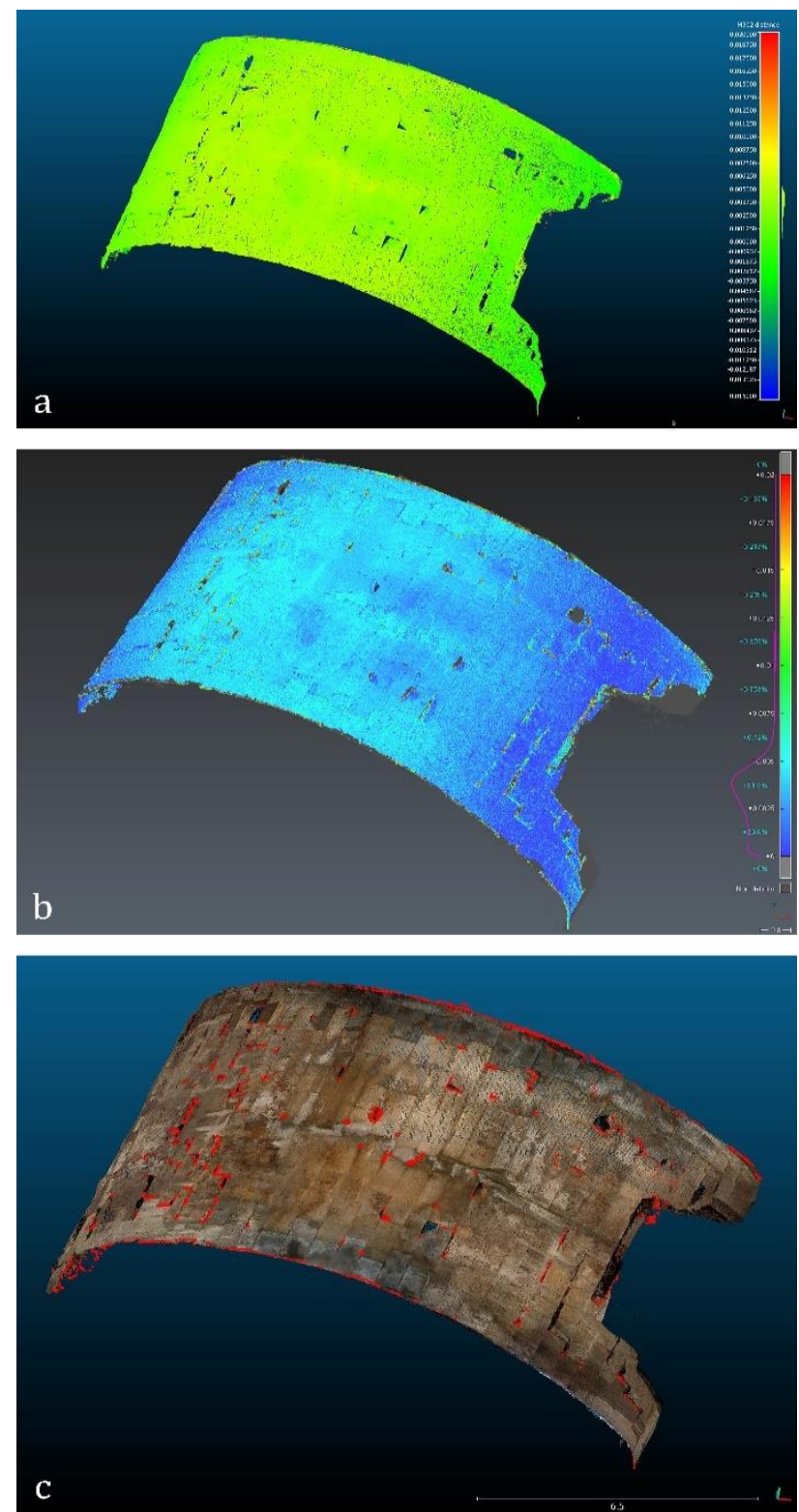

Figure 6. Comparison between TLS and SLR point clouds: a) 3D model with M3C2 distances b) 3D model of distances computed with 3DReshaper c) 3D model with, in red, the area in which the change is significant, considering the registration error of the TLS point cloud on the georeferenced targets (paragraph 3). 


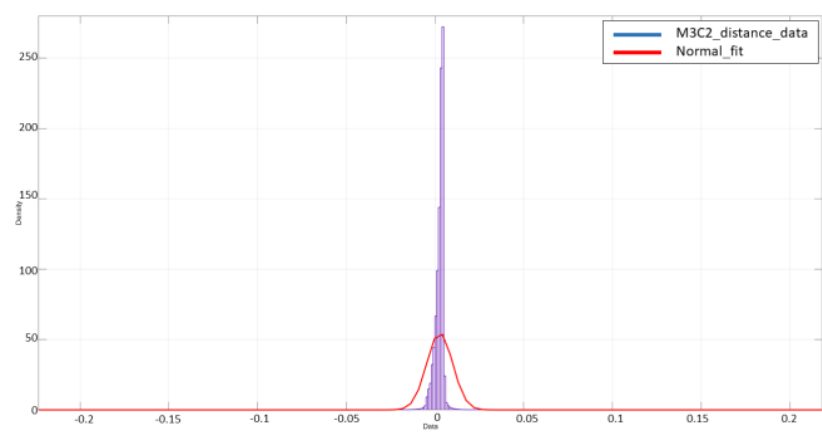

Figure 7. TLS-SLR comparison: histograms of all the M3C2 distance values and their normal distribution fitting.

\begin{tabular}{|l|l|}
\hline $\begin{array}{l}\text { M3C2 distance Laser Scanning-SLR camera } \\
\text { (1231528 values) }\end{array}$ \\
\hline Mean $[\mathrm{m}]$ & 0.0027 \\
\hline Std. dev. $[\mathrm{m}]$ & 0.0072 \\
\hline Absolute mean $[\mathrm{m}]$ & 0.0037 \\
\hline Min. value $[\mathrm{m}]$ & -0.2187 \\
\hline Max. value $[\mathrm{m}]$ & 0.2133 \\
\hline
\end{tabular}

Table 4. Basic statistics about M3C2 distance data from TLSSLR analysis.

The TLS-SLR comparison shows a mean distance of $0.0027 \mathrm{~m}$, with a standard deviation of $0.0072 \mathrm{~m}$ and an absolute mean (that does not consider the sign of the values) that increase to $0.037 \mathrm{~m}$.

The TLS-GoPro comparison shows a mean distance of -0.0003 $\mathrm{m}$, with a standard deviation of $0.0091 \mathrm{~m}$ and an absolute mean (that does not consider the sign of the values) that increases to $0.050 \mathrm{~m}$.

In addition to point cloud analysis, some sections in representatives parts of the arch have been produced from 3D models and they have been used for further distance calculation along the curved geometry of the bridge, with the aim of detecting a trend, possibly influenced by the architectural geometry. 3D Reshaper allows this computation that is showed in Figure 10.

Furthermore one last observation has been made on an indentation of the arch surface, in correspondence with a deteriorated stone. The intent was to investigate an example of a problematic part to detect the completeness and the level of detail of the different models out of the main surface of the structure (Figure 11).

\section{DISCUSSION}

The results of the comparison between the different 3D models detect, generally, a good reconstruction of the geometry of the arch with SfM tecniques comparing with TLS reference.

The means quite close to zero and the absolute means that does not exceed the $5 \mathrm{~mm}$ shows a good proximity of the reconstructed dense point clouds to the reference. The distance values have to be considered in relation to the intrinsic error of the applied methodologies.
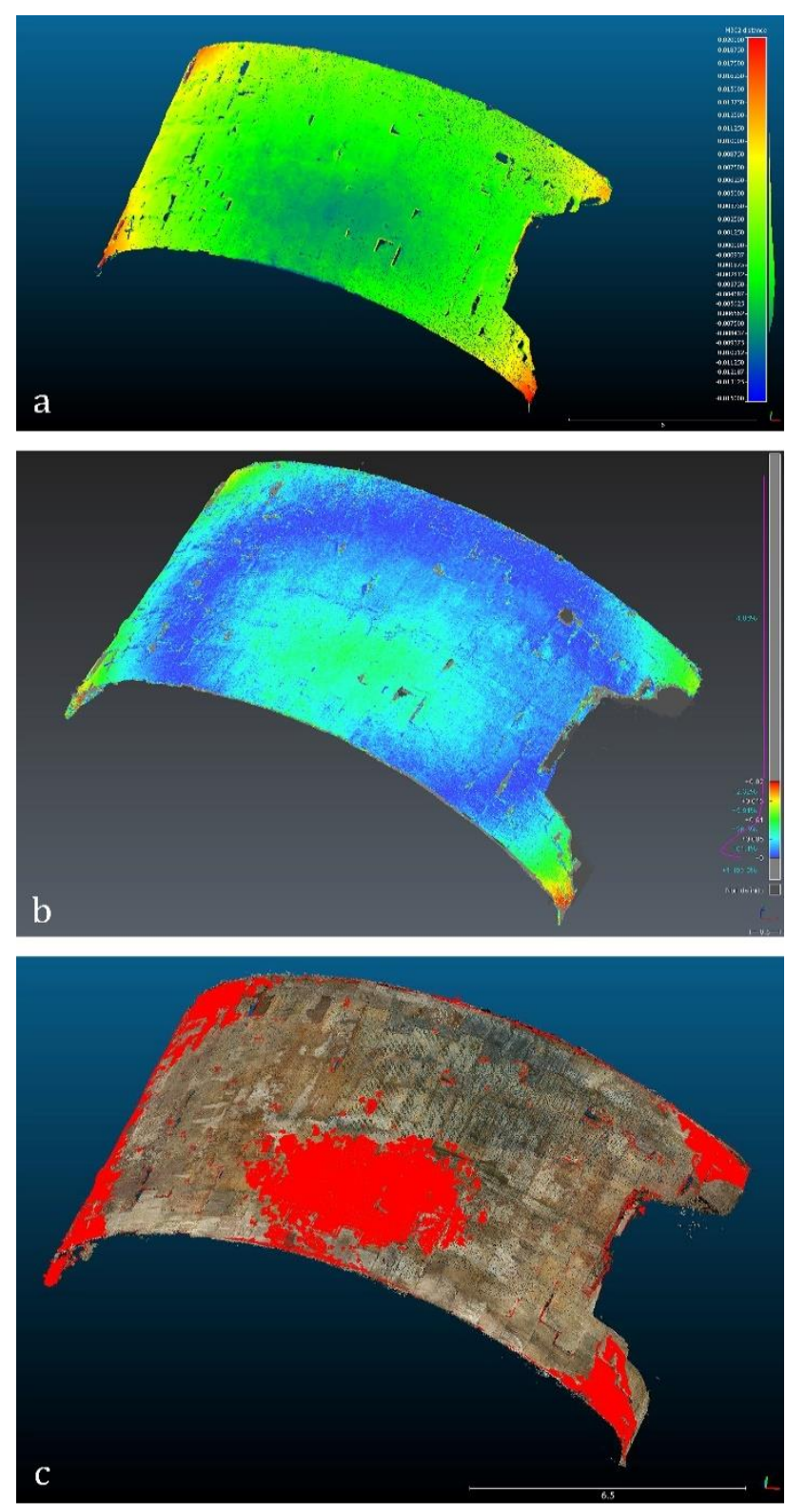

Figure 8. Comparison between TLS and GoPro point clouds: a) 3D model with M3C2 distances b) 3D model of distances computed with 3DReshaper c) 3D model with, in red, the area in which the change is significant, considering the registration error of the TLS point cloud on the georeferenced targets (paragraph 3).

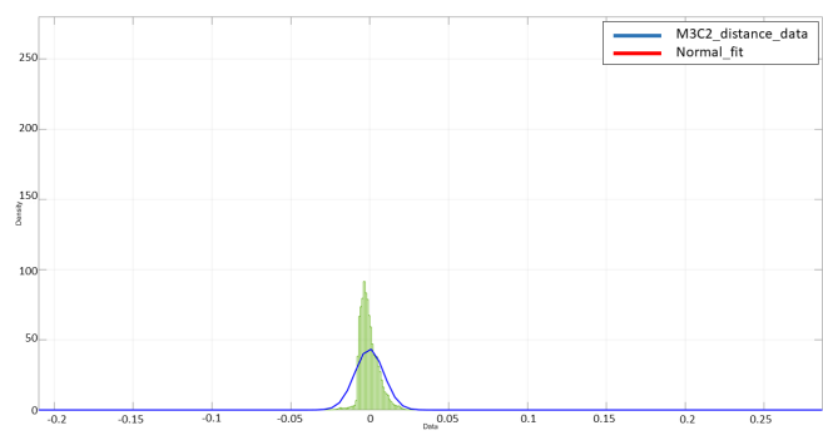

Figure 9. TLS-GoPro comparison: histograms of all the $\mathrm{M} 3 \mathrm{C} 2$ distance values and their normal distribution fitting. 


\begin{tabular}{|l|l|}
\hline $\begin{array}{l}\text { M3C2 distance Laser Scanning-GoPro camera } \\
\text { (1151842 values) }\end{array}$ \\
\hline Mean $[\mathrm{m}]$ & -0.0003 \\
\hline Std. dev. $[\mathrm{m}]$ & 0.0091 \\
\hline Absolute mean $[\mathrm{m}]$ & 0.0050 \\
\hline Min. value $[\mathrm{m}]$ & -0.2040 \\
\hline Max. value $[\mathrm{m}]$ & 0.2815 \\
\hline
\end{tabular}

Table 5. Basic statistics about M3C2 distance data from TLSSLR analysis.
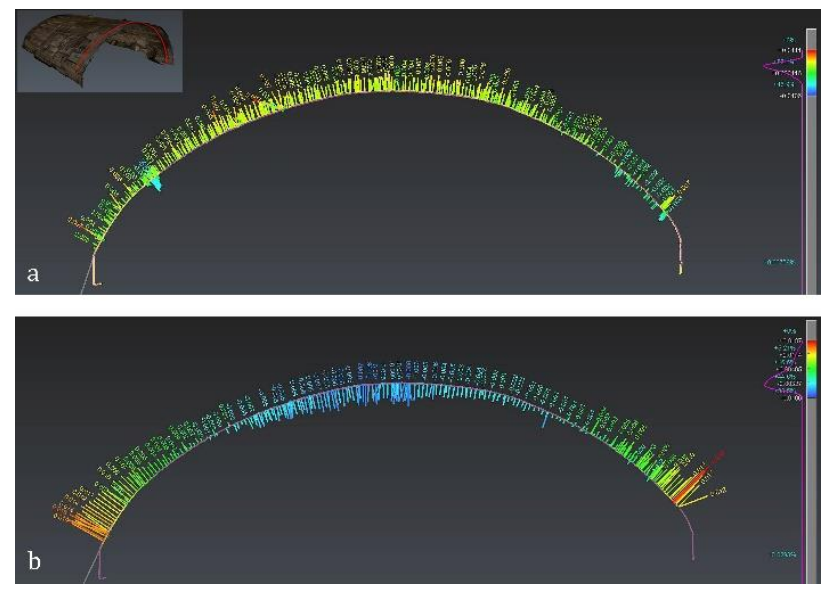

Figure 10. Results of the linear objects inspection by 3D Reshaper: a) Distances between TLS and SLR models; b)

Distances between TLS and GoPro models. Distance values are related to the color of the scale bar and to the length of the vectors (lengths are magnified to better show the trend and the geometric differences).

Topographic measures affect the accuracies on the targets (TLS) and markers (photogrammetry) coordinate in the order of a 2 $\mathrm{mm}$ standard deviation on the single measurement. The accuracy on the target measurement by the laser scanner is, as declared by the manufacturer, of $2 \mathrm{~mm}$ standard deviation so, according to the propagation of error, an approximated total value of $3 \mathrm{~mm}$ has to be considered. This is comparable with the error registration of $3 \mathrm{~mm}$ resulting from the registration/georeferencing of the TLS scan on the targets.

The SfM images processing has produced two models from SLR camera and GoPro acquisitions. In addition to the software reports, that show the values of GSD and error on control and check points, the further comparison performed on $3 \mathrm{D}$ model gives more detailed information about quality of the models, reliability and problematic aspects.

As reported in the results paragraph (Figures 6, 7 and Table 4) the SLR model shows an optimal reconstruction of the geometry of the arch, with a general mean distance of $2 \mathrm{~mm}$ (and absolute mean of $3 \mathrm{~mm}$ ), that looks like a rigid translation of the whole model that does not compromise its morphological correctness. Furthermore the standard deviation of $7 \mathrm{~mm}$ represents a narrow distribution of the distance values. The mean shift can be considered within the methodological uncertainty.
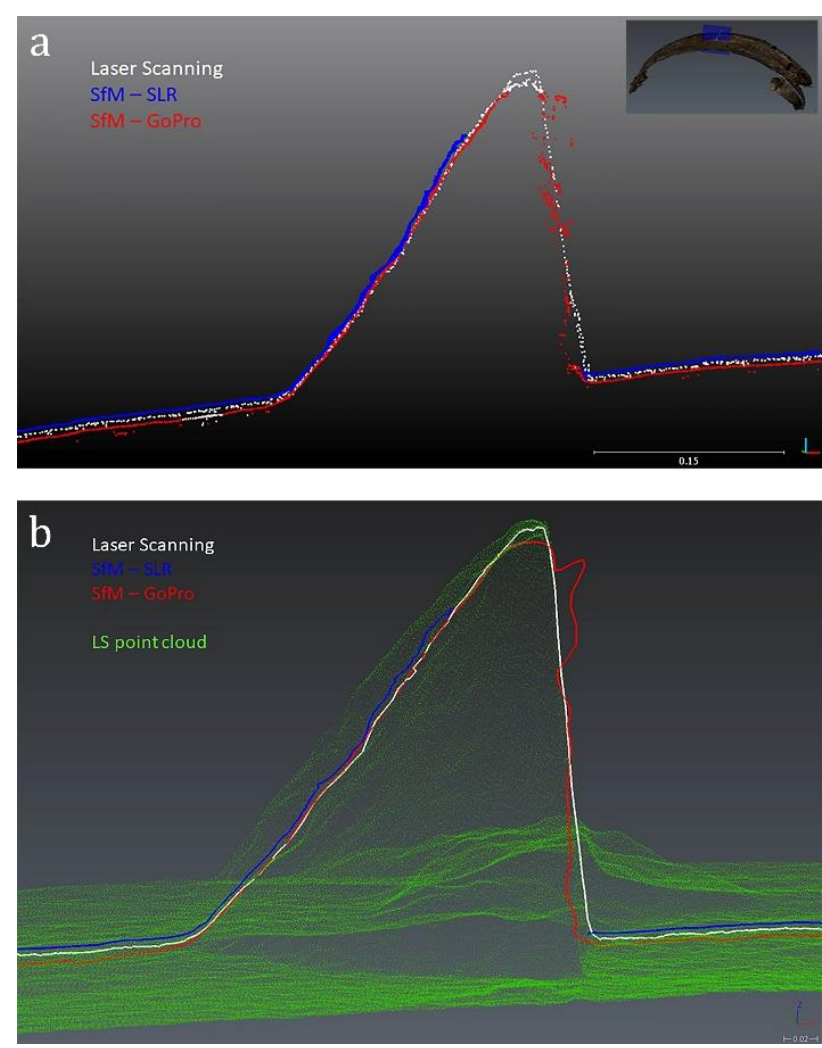

Figure 11. Observation of the models variations in correspondence with a deteriorated stone: a) How the points of the point clouds detect the real geometry; b) The interpolated polylines from the same points.

The GoPro model requires, on the other hand, some different evaluations. The comparison results (Table 13) and the Figures 11 and 13 show a wider variability on the distance values, with areas that diverge positively or negatively from the reference model. As well highlighted in Figure 10 there is symmetry in the differences, with a flattening of the arch geometry, that produce peaks of positive distances near the bases and peaks of negative distances in correspondence of the top of the intrados. These areas are well pointed out in the model of significant change (Figure 8c) that considers the differences that exceed the registration error of TLS point cloud. The mean very close to zero $(-0.3 \mathrm{~mm})$ is not equivalent to a global geometrical fitting, in fact the absolute mean of $5 \mathrm{~mm}$ and a standard deviation of 9 $\mathrm{mm}$ better represent the real differences.

For its part (in this case study) the GoPro has provided better results, in completeness of the point cloud, in an investigated indentation of the surface due to the stone deterioration (Figure 11). Although with a more noisy point cloud than the laser scanning, the GoPro has allowed the reconstruction of the entire part of the cavity. SLR camera have not produced points in the deeper part. This is likely due to the wider field of view of the action camera that permits an higher overlap that, for some specific problems, is more effective that the use of less images with higher quality.

\section{FURTHER PROCESSING: RETOPOLOGY FOR VR}

The attention paid to accuracy during the surveying phase is mainly addressed to reasons of historic and scientific research. How this topic is faced when working on the side of dissemination, especially when digitally conveyed, is the topic 
of this final paragraph. In this case clarity and lightness are the key words, but details are still significant.

The creation of triangular meshes still provides a model with an high level of detail that is returned through a large number of triangular polygons. Such a number of faces is difficult to be managed in software for real-time rendering, especially when dealing with artifacts of such huge dimensions. It is therefore necessary to proceed to a mesh optimization phase, called retopology. It could be managed automatically through software such as Instant Mesh, which allows a considerable reduction of the number of polygons, guaranteeing an almost total absence of triangular polygons and producing a so-called quad mesh (with quadrangular polygons) or manually through the use of an add on by Blender $3 \mathrm{~d}$ called Retopoflow. The manual approach, although less rapid, allows a more accurate control of the development of surfaces (especially where two planes intersect) and generates less polygons than the automatic method, lightening the file even more. This operation, in both cases turns the model to an order of thousands or hundreds of polygons. The two methods respect the general patterns of the surfaces by generating a simple mesh, perfectly comparable to the complex one.
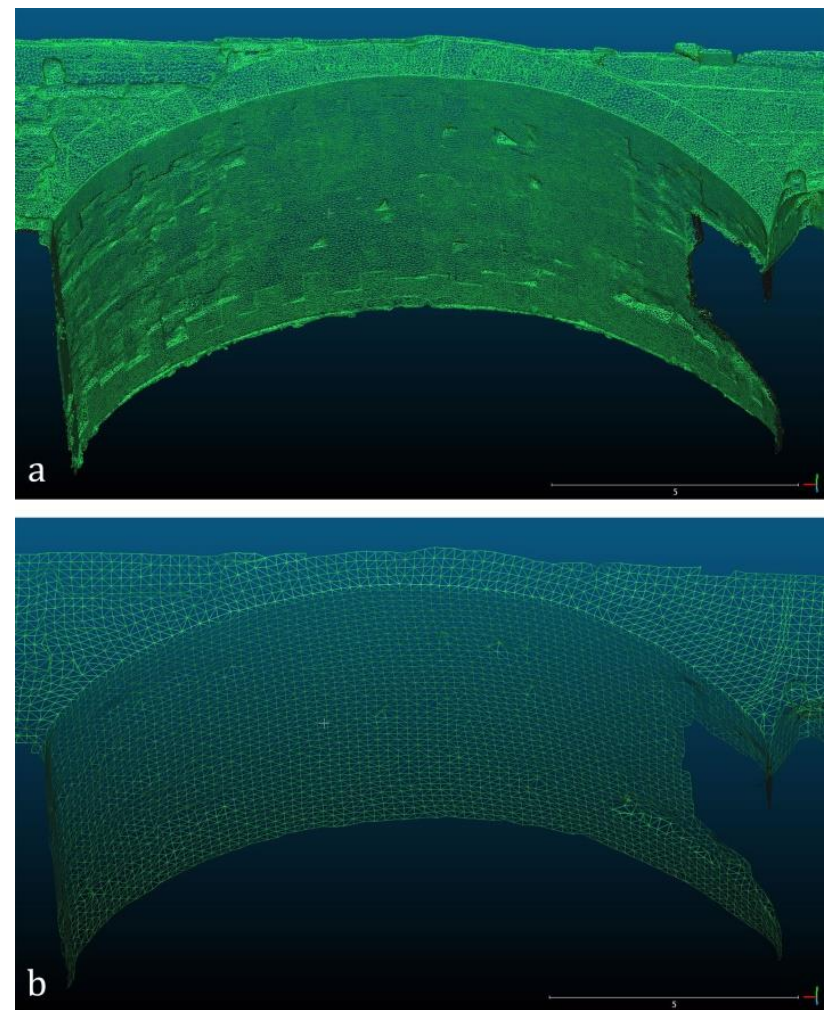

Figure 12. Representation of: a) the complex mesh; b) the simplified mesh after its retopology.

The level of detail is obviously lower in the simplified version of the model than in the original mesh, so the workflow can be improved: once the UV map of the artifact has been established, a baking operation is carried out. It allows to project the detail of the complex mesh on the simple one by means of a normal map, an RGB image that simulates the variations in the intensity of light that strikes an irregular and complex surface. The details that were previously rendered by means of polygons, are now obtained through a texture and it greatly speeds up the rendering operations. Baking can also be used to better structure the diffuse map (or albedo). Making a comparison between the complex mesh and the simple one supplied with normal map, it can be seen that the shown level of detail is almost unchanged. Though geometrically not-inspectable, they still witness the complexity of the geometry.

\section{CONCLUSIONS}

The analysis of the survey of one of the arches of the Roman bridge of San Lorenzo has investigated the application on a particular architectural curve structure, in a difficult environmental context.

The results of the comparisons confirm, as widely noticed in bibliography, a high reliability for the 3D photogrammetric survey by SfM technique. In addition, a little gap between the SLR and the action camera products have been found in this study. The comparison between the two photogrammetric clouds shows similar outputs, with an optimal geometrical correspondence for the SLR model whose errors largely stay in the range of the methodological accuracy.

The same remark applies to the GoPro model, even if the differences are more relevant and an almost symmetric geometrical distortion highlights some more critical parts to be reconstructed.

Further analysis of the quality of the models could be performed on similar objects in the field of $\mathrm{CH}$, by applying the same tools and workflow (Figure 13).

Such a comparison proves to be very useful in order to provide $\mathrm{CH}$ experts with an index of reliability of the photogrammetric method that has spread widely in their research branch, usually replacing still expensive lasers.

Moreover, results are significant for continuing the project "PD Invisible" and for a strategic planning of the survey of next selected monuments. Since the scientific target of this project, such an assessment was an essential step. The aforementioned purposes of dissemination and sharing of $3 \mathrm{D}$ models with $\mathrm{AR}$ applications will force a simplification of the meshes, in order to obtain models that could easily be processed by a smartphone or a similar device. Nevertheless, metric and geometric reliable point clouds are the necessary data source.

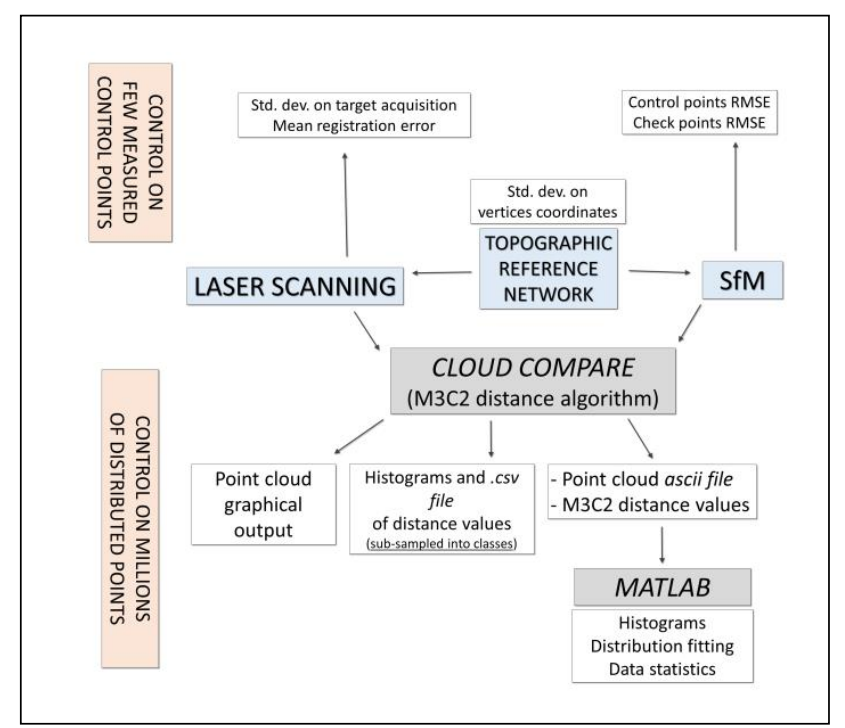

Figure 13. Workflow of the comparison procedure applied to this case study. 


\section{ACKNOWLEDGEMENTS}

The activity presented in the paper is part of the research grant "FSE 2105-18-11-2018, PD-Invisible: PaDova INnovative VISions - visualizations and Imaginings Behind the city Learning". We would like to express our appreciation to Comune di Padova, Musei Civici agli Eremitani and Soprintendenza Archeologia, Belle Arti e Paesaggio per l'area metropolitana di Venezia e le province di Belluno, Padova e Treviso for the endorsement and the collaboration.

\section{AUTHORS CONTRIBUTIONS}

Introduction: AMa

State of art: FC

Laser scanning and photogrammetric survey: FC, MM, AMe

Models comparison: MM, FC

Results: MM, FC

Discussion: $\mathrm{MM}$

Further processing: retopology for VR: MP, CC

Conclusions: FC, MM

Supervision: JB, VA, AG

\section{REFERENCES}

Balletti, C., Guerra, F., Tsioukas, V., Vernier, P., 2014. Calibration of action cameras for photogrammetric purposes. Sensors, 14(9), 17471-17490.

Baltsavias, E.P., 1999. A comparison between photogrammetry and laser scanning. ISPRS Journal of Photogrammetry and Remote Sensing, 54 (2-3), 83-94.

Boehler, W., Vicent, M. B., Marbs, A., 2003. Investigating laser scanner accuracy. Int. Arch. Photogramm. Remote Sens. Spatial Inf. Sci., 34(5), 696-701.

Bolognesi, M., Furini, A., Russo, V., Pellegrinelli, A., Russo, P., 2014. Accuracy of cultural heritage 3D models by RPAS and terrestrial photogrammetry. Int. Arch. Photogramm. Remote Sens. Spatial Inf. Sci., 40(5), 113-119.

Bonetto, J., Pettenò, E., Veronese, F., 2017. Padova. La città di Tito Livio. Cleup, Padova.

Bosche, F. N., Forster, A. M., Valero, E., 2015. 3D surveying technologies and applications: point clouds and beyond. HeriotWatt University, Edinburgh.

Broome, L., 2016. Comparison between terrestrial close range photogrammetry and terrestrial laser scanning. Bachelor of Spatial Science dissertation, Faculty of Health, Engineering and Sciences, University of Southern Queensland.

Calantropio, A., Patrucco, G., Sammartano, G., Losè, L.T., 2018. Low-cost sensors for rapid mapping of cultural heritage: first tests using a COTS Steadicamera. Applied Geomatics, 10(1), 31-45.

Fiorillo, F., Limongiello, M., Fernández-Palacios, B. J., 2016. Testing GoPro for 3D model reconstruction in narrow spaces. Acta IMEKO, 5(2), 64-70.
Fraser, C. S., 2013. Automatic camera calibration in close range photogrammetry. Photogrammetric Engineering \& Remote Sensing, 79(4), 381-388.

Galliazzo, V., 1971. I ponti di Padova Romana. Saggio di archeologia urbanistica. Cedam, Padova.

Grussenmeyer, P., Landes, T., Voegtle, T., Ringle, K., 2008. Comparison methods of terrestrial laser scanning, photogrammetry and tacheometry data for recording of cultural heritage buildings. Int. Arch. Photogramm. Remote Sens. Spatial Inf. Sci., 37(5), 213-218.

Guarnieri, A., Vettore, A., Remondino, F., 2004. Photogrammetry and ground-based laser scanning: assessment of metric accuracy of the 3D model of Pozzoveggiani church. Proceedings of FIG working week (2004), the olympic spirit in surveying, Athens.

Lague, D., Brodu, N., Leroux, J., 2013. Accurate 3D comparison of complex topography with terrestrial laser scanner: Application to the Rangitikei canyon (NZ). ISPRS Journal of Photogrammetry and Remote Sensing, 82, 10-26.

Lichti, D. D., Gordon, S. J., 2004. Error propagation in directly georeferenced terrestrial laser scanner point clouds for cultural heritage recording. Proceedings of FIG working week (2004), the olympic spirit in surveying, Athens.

Micheletti, N., Chandler, J. H., Lane, S. N., 2015. Investigating the geomorphological potential of freely available and accessible structure-from-motion photogrammetry using a smartphone. Earth Surface Processes and Landforms, 40(4), 473-486.

Remondino, F., Fraser, C., 2006. Digital cameras calibration methods: considerations and comparisons. Int. Arch. Photogramm. Remote Sens. Spatial Inf. Sci., 36(5), 266-272. 